Prepared for the U.S. Department of Energy

under Contract DE-AC05-76RL01830

\title{
LESSONS LEARNED \\ Biosurveillance Mobile App \\ Development Intern Competition \\ (Summer 2013)
}

CF Noonan

MJ Henry

CD Corley

November 2013

\section{Pacific Northwest}

NATIONAL LABORATORY

Proudly Operated by Baltelle Since 1965 


\title{
DISCLAIMER
}

This report was prepared as an account of work sponsored by an agency of the United States Government. Neither the United States Government nor any agency thereof, nor Battelle Memorial Institute, nor any of their employees, makes any warranty, express or implied, or assumes any legal liability or responsibility for the accuracy, completeness, or usefulness of any information, apparatus, product, or process disclosed, or represents that its use would not infringe privately owned rights. Reference herein to any specific commercial product, process, or service by trade name, trademark, manufacturer, or otherwise does not necessarily constitute or imply its endorsement, recommendation, or favoring by the United States Government or any agency thereof, or Battelle Memorial Institute. The views and opinions of authors expressed herein do not necessarily state or reflect those of the United States Government or any agency thereof.

\author{
PACIFIC NORTHWEST NATIONAL LABORATORY \\ operated by \\ BATTELLE \\ for the \\ UNITED STATES DEPARTMENT OF ENERGY \\ under Contract DE-AC05-76RL01830 \\ Printed in the United States of America \\ Avalable to DOE and DOE contractors from the \\ Office of Scientific and Technical Information, \\ P.O. Box 62, Oak Ridge, TN 37831-0062; \\ ph: (865) 576-8401 \\ fax: (865) 576-5728 \\ email: reports $a$ adonis.osti.gov \\ Available to the public from the National Technical Information Service \\ 5301 Shaw nee Rd., Alexandria, VA 22312 \\ ph: (800) 553-NTIS (6847) \\ email: ondersa ntis.gov chttp:/www.ntis.gov/about/form,asps> \\ Online ordering: http:/www.atis.gov
}




\title{
LESSONS LEARNED
}

\section{Biosurveillance Mobile App Development Intern Competition (Summer 2013)}

\author{
CF Noonan \\ MJ Henry \\ CD Corley
}

November 2013

Prepared for

the U.S. Department of Energy

under Contract DE-AC05-76RL01830

Pacific Northwest National Laboratory

Richland, Washington 99352 



\section{Contents}

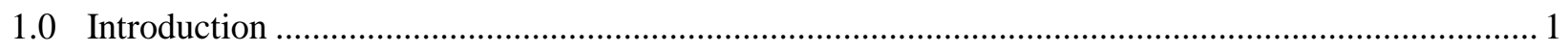

2.0 BEOWulf: Biosurveillance EcOsystem Workbench ................................................................. 1

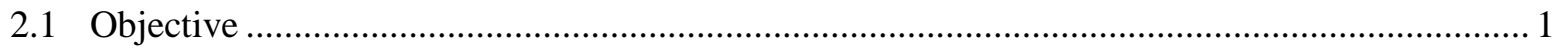

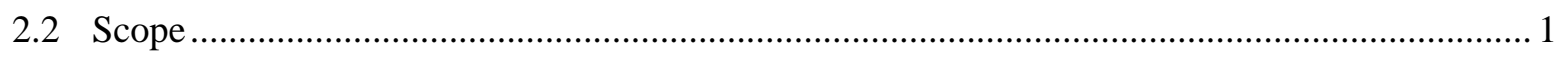

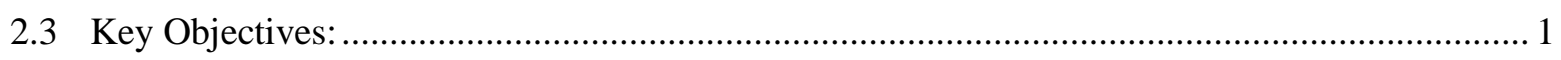

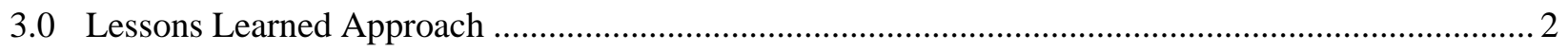

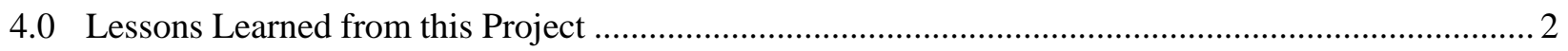

5.0 Lessons Learned Knowledge Base/Database ............................................................................ 2

6.0 Lessons Learned Applied from Previous Projects ...................................................................... 2

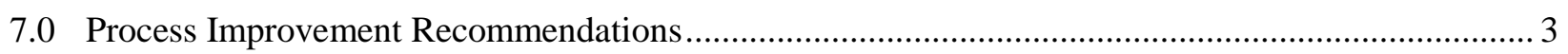

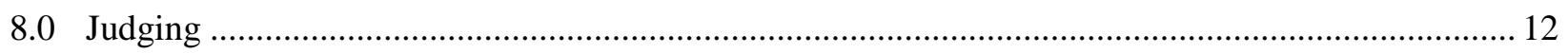

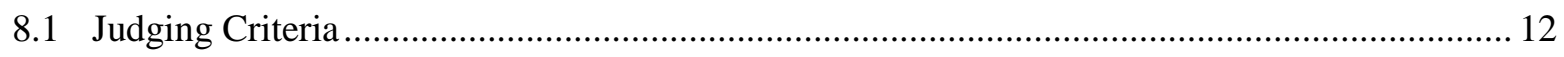

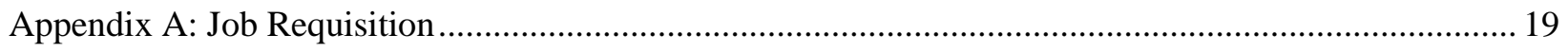

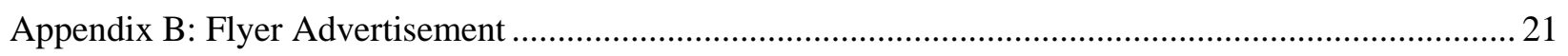

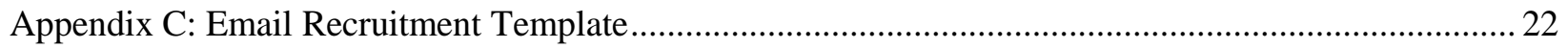

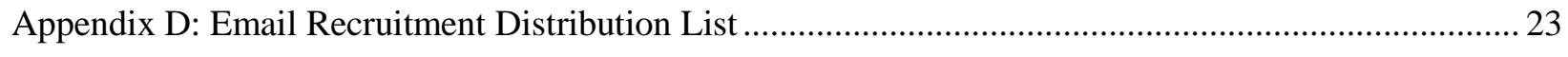

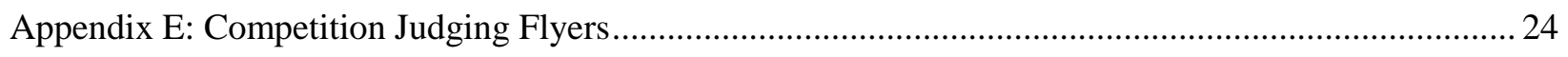

\section{Tables}

Table 1. High-level Lessons Learned from the BEOWulf Mobile App Development Competition... 4

Table 2. Risks and Issues ....................................................................................................... 8

Table 3. Software Quality Assurance Process Improvement Recommendations ............................. 9

Table 4. Vendor Management Process Improvement Recommendations ........................................ 10

Table 5. Other Process Improvement Recommendations ................................................................ 11

Table 6. Judges Feedback for the Android Team App, FoodFeed ................................................... 12

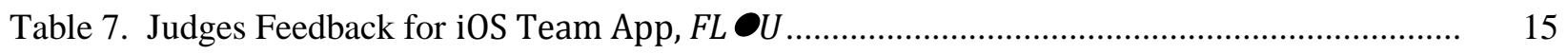





\subsection{Introduction}

The purpose of the lessons learned document for the BEOWulf Biosurveillance Mobile App Development Intern Competition is to capture the project's lessons learned in a formal document for use by other project managers on similar future projects. This document may be used as part of new project planning for similar projects in order to determine what problems occurred and how those problems were handled and may be avoided in the future. Additionally, this document details what went well with the project and why, so that other project managers may capitalize on these actions. Project managers may also use this document to determine who the project team members were in order to solicit feedback for planning their projects in the future. This document will be formally communicated with the organization and will become a part of the organizational assets and archives.

\subsection{BEOWulf: Biosurveillance EcOsystem Workbench}

\subsection{Objective}

To develop an Internet-based Biosurveillance EcOsystem Workbench (BEOWulf) that integrates transformational analytical capabilities to radically improve U.S. government and interagency efficiency and effectiveness in support of threat surveillance, including the detection, investigation, and response to infectious disease events. Pacific Northwest National Laboratory (PNNL) will also deliver three mobile phone applications developed through a teamed student competition. The successful creation of an advanced analytic workbench and the mobile applications will 1) improve the understanding of disease baseline and event prediction related to human social, cultural, and behavioral data; environmental/climatological data; disease risk mapping; and 2) enable users to predict, alert, forecast and manage a biothreat event — whether emerging, endemic, or intentionally introduced — within 24 hours to minimize harmful impact to the warfighter and society.

\subsection{Scope}

Develop a suite of analytical services leveraging PNNL's deep expertise in text, social media, and visual analytics. A Biosurveillance EcOsystem Workbench (BEOWulf) will be developed to serve as the biosurveillance users' source for analysis tools, providing them with the means of rapidly analyzing data. The user experience will be customizable to meet different workflow requirements (e.g., commander, public health analyst, research scientist). We will adapt new and existing advanced predictive analytical tools and mathematical methods (including machine learning, data assimilation, scan statistics, epidemic models, anomaly detection, confidence level analysis) to support analytic needs. State-of-the-art tools will enable users to define expected and known relationships between multiple sources of information (e.g., medical assays and environmental data).

\subsection{Key Objectives}

- $\quad$ Design and develop a Biosurveillance EcOsystem Workbench 
- Bring to bear PNNL's deep analytical toolset in visual text and multimedia analytics

- Investigate the appropriate use of text and multimedia analytics for biosurveillance

- Host a student competition to develop mobile phone applications supporting BSV

\subsection{Lessons Learned Approach}

The lessons learned from the BEOWulf Biosurveillance Mobile App Development Intern Competition were gathered from both realized and unrealized risks as well as through interviews with project team members and other stakeholders as necessary. The lessons learned from this project are to be used as references for future projects and contain an adequate level of detail so that other project managers may have enough information on which to help base their project plans. The lessons learned in this document are categorized by project knowledge area. These knowledge areas consist of: procurement management, risk management, integration management, quality management, time management, cost management, scope management, human resource management, and communications management. NOTE: some knowledge areas may not contain lessons learned if none were documented throughout the project lifecycle.

\subsection{Lessons Learned from this Project}

Table 1 (page 4) lists the major lessons learned for the BEOWulf Biosurveillance Mobile App Development Intern Competition. These lessons are categorized by project knowledge area and descriptions, impacts, and recommendations are provided for consideration on similar future new construction projects. It is important to note that not only failures or shortcomings are included but successes as well.

\subsection{Lessons Learned Knowledge Base/Database}

The lessons learned for the BEOWulf Biosurveillance Mobile App Development Intern Competition will be contained in the organizational lessons learned knowledge base maintained by the project management office. This information will also be archived in the BEOWulf project records for future reference. This information will be valuable for any project manager wishing to undertake a student intern competition at Pacific Northwest National Laboratory (PNNL) in the future.

\subsection{Lessons Learned Applied from Previous Projects}

To our knowledge this was the first student intern competition hosted at PNNL. As such there were no historical lessons learned to reference in the development of this project. 


\subsection{Process Improvement Recommendations}

As indicated in Table 1, the BEOWulf Biosurveillance Mobile App Development Intern Competition was successful in a variety of perspectives. Over 71 resumes were received, of those 40 candidates met the position requirements. Then $25-30 \%$ of them were interviewed. Nine students were extended offers and seven were successful through the onboarding process. All but one of the seven interns were foreign nationals, prompting additional security measures and pre-processing during the hiring process. The competition was designed as a team-based competition, where the PNNL staff formed the teams before the interns arrived. Careful consideration went into developing the team to be as balanced in skills and experience as possible. Subsequently, we have enumerated lessons learned with respect to human resources, procurement, security, planning, and execution in order to aid future efforts with the design and implementation of similar challenges at a federally funded research and development center (FFRDC). 
Table 1. High-level Lessons Learned from the BEOWulf Mobile App Development Competition

\begin{tabular}{|c|c|c|c|c|}
\hline Category & Issue Name & Problem/Success & Impact & Recommendation \\
\hline \multirow[t]{4}{*}{$\begin{array}{l}\text { Procurement } \\
\text { Management }\end{array}$} & Facilities & $\begin{array}{l}\text { Traditionally used intern spaces } \\
\text { were at maximum capacity. The } \\
\text { Knowledge Discovery \& } \\
\text { Informatics Viz Lab (ISB } 1 / 416 \text { ) was } \\
\text { converted into a mobile app } \\
\text { development laboratory. }\end{array}$ & $\begin{array}{l}\text { While we initially scrambled for space to } \\
\text { fit nine interns, converting an existing } \\
\text { Lab space for this project was extremely } \\
\text { valuable. The dedicated space allowed for } \\
\text { camaraderie, group meetings and } \\
\text { interaction, etc. }\end{array}$ & $\begin{array}{l}\text { More lead time would have enabled } \\
\text { the space to be fully set-up and } \\
\text { prepared prior to the intern's arrival } \\
\text { on campus. }\end{array}$ \\
\hline & $\begin{array}{l}\text { Computers, } \\
\text { Mobile } \\
\text { devices, } \\
\text { software, etc. }\end{array}$ & $\begin{array}{l}\text { Existing computers were formatted } \\
\text { for the students. Required mobile } \\
\text { devices and software were acquired } \\
\text { using a P-card after the students } \\
\text { arrived at PNNL. The time lag was } \\
\text { not significant but potentially could } \\
\text { have added to unnecessary } \\
\text { development delays. }\end{array}$ & $\begin{array}{l}\text { Having computers on hand saved quite a } \\
\text { bit of time and money. }\end{array}$ & $\begin{array}{l}\text { Purchase equipment prior to the } \\
\text { intern's arrival on campus. }\end{array}$ \\
\hline & Prizes & $\begin{array}{l}\text { We had planned for the winning } \\
\text { team to receive a tablet of their } \\
\text { choice. However, after engaging } \\
\text { staff in Legal, Payroll, and }\end{array}$ & $\begin{array}{l}\text { The winning team members each received } \\
\$ 1000.00 \text {. The runner-up team members } \\
\text { each received } \$ 500.00 \text {. }\end{array}$ & $\begin{array}{l}\text { Awarding cash bonuses is the } \\
\text { preferred method of reward for } \\
\text { interns, is cost effective, 'clean' and } \\
\text { easy to initiate. }\end{array}$ \\
\hline & & $\begin{array}{l}\text { Accounting, and reviewing PNSO } \\
\text { and DOE guidelines, we discovered } \\
\text { that this was not possible. In lieu of } \\
\text { purchasing tablets, we provided a } \\
\text { cash bonus. }\end{array}$ & $\begin{array}{l}\text { Providing cash bonuses was the preferred } \\
\text { route and was permitted under PNNL } \\
\text { contracts with DOE and the client. }\end{array}$ & \\
\hline $\begin{array}{l}\text { Human } \\
\text { Resources } \\
\text { Management }\end{array}$ & Recruitment & $\begin{array}{l}\text { The timing of the mobile app } \\
\text { competition was extremely tight. } \\
\text { After receiving notification of the } \\
\text { proposal award (March, 2013), we } \\
\text { had to recruit prior to receipt of the } \\
\text { first installment of project funds. } \\
\text { The job requisitions were published } \\
\text { in May, which is often late in the } \\
\text { game to recruit students for a } \\
\text { summer internship. }\end{array}$ & $\begin{array}{l}\text { Initially we had desired three teams of } \\
\text { three students - one team each for iOS, } \\
\text { Android and Windows mobile devices. } \\
\text { Over } 70 \text { resumes were received in } \\
\text { response to the undergraduate and } \\
\text { graduate student requisitions. Of these we } \\
\text { interviewed } 25-30 \% \text {. } \\
\text { Offers were made to nine students. Three } \\
\text { of our top picks declined due to } \\
\text { competing offers and/or availability } \\
\text { conflicts. Second tier candidates were } \\
\text { pursued, one of whom was able to accept } \\
\text { the offer. The other encountered } \\
\text { immigration issues and would not make }\end{array}$ & $\begin{array}{l}\text { Recruit as early as possible. Target } \\
\text { specific colleges/universities that } \\
\text { have strong programs in mobile app } \\
\text { development, user interaction, and } \\
\text { graphic design. }\end{array}$ \\
\hline
\end{tabular}




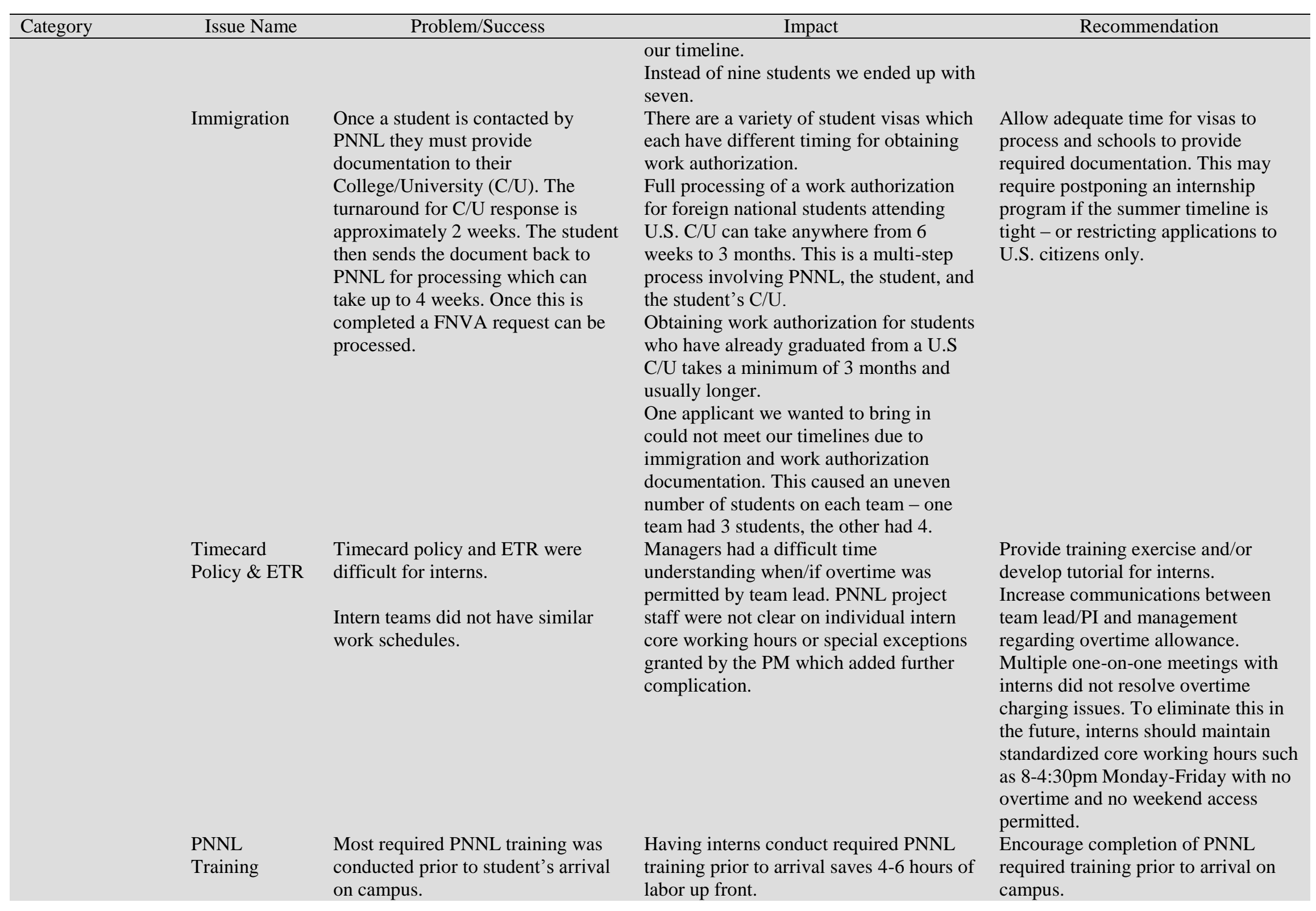




\begin{tabular}{|c|c|c|c|c|}
\hline Category & Issue Name & Problem/Success & Impact & Recommendation \\
\hline \multirow[t]{2}{*}{$\begin{array}{l}\text { Scope } \\
\text { Management }\end{array}$} & Project Timing & $\begin{array}{l}\text { See Human Resources section } \\
\text { above. }\end{array}$ & & \\
\hline & $\begin{array}{l}\text { Mobile App } \\
\text { Development }\end{array}$ & $\begin{array}{l}\text { The mobile app development task } \\
\text { was scoped adequately for the time } \\
\text { period allotted ( } 10 \text { weeks). }\end{array}$ & & $\begin{array}{l}\text { Accurately assess the skills level of } \\
\text { interns (and entire teams) prior to } \\
\text { hire. If skills are not up to par the } \\
\text { timeframe for app development may } \\
\text { not be adequate. }\end{array}$ \\
\hline Quality & Software QA & See Quality Defects (Table 4) & & \\
\hline Management & Teaming & $\begin{array}{l}\text { One of the seven students was } \\
\text { unable to complete the full term of } \\
\text { the internship due to early arrival on } \\
\text { campus for TA training. While this } \\
\text { may not have been unavoidable, the } \\
\text { student should have informed } \\
\text { PNNL of the possibility s/he would } \\
\text { be exiting early. }\end{array}$ & $\begin{array}{l}\text { Inability to participate the full duration of } \\
\text { the internship placed undue hardship on } \\
\text { the iOS mobile app team. }\end{array}$ & $\begin{array}{l}\text { As much as possible, enforce specific } \\
\text { duration of time in service for the } \\
\text { internship. }\end{array}$ \\
\hline $\begin{array}{l}\text { Risk } \\
\text { Management }\end{array}$ & $\begin{array}{l}\text { Foreign } \\
\text { Nationals \& CI }\end{array}$ & $\begin{array}{l}\text { Six of the seven interns were } \\
\text { foreign nationals. This prompted } \\
\text { internal concerns regarding project } \\
\text { work and exposure to other work }\end{array}$ & $\begin{array}{l}\text { Management, PI and other project staff } \\
\text { (lead mentor, alternate mentor) met with } \\
\text { CI to discuss working with foreign } \\
\text { nationals, brief CI on the project and }\end{array}$ & $\begin{array}{l}\text { Meet with CI staff and receive a } \\
\text { briefing. Provide intern resumes to CI } \\
\text { directly for expeditious review. }\end{array}$ \\
\hline
\end{tabular}

being conducted in to other work

client, etc. This meeting provir

baseline for project staff on what to be

See also Immigration under Human Resources above.

Computer To alleviate management concerns Security about foreign nationals working on NSD projects, we asked

Unclassified Computer Security to run weekly scans on the machines.

Core Working Interns were permitted core working Hours / hours to ISB1 - Monday-Friday,

Facility access 6 am to $6 \mathrm{pm}$.

See also Timecard Policy \& ETR under Human Resources above.

One computer was identified as suspicious after the interns exited. It was removed from the network.

Interns often asked to work beyond $6 \mathrm{pm}$, work overtime or come in on weekends.

When the PI approved he had to essentially "escort" the interns. On at

least one occasion the PI came in to work on the weekend and the requesting intern did not show up.

Overtime hours could not easily be validated.
Interns are more likely than staff to have lackadaisical computer security practice/habits. Being proactive and running weekly scans is recommended to protect internal files/systems.

Maintain core working hours with no opportunity for overtime or weekend work. 


\begin{tabular}{|c|c|c|c|c|}
\hline Category & Issue Name & Problem/Success & Impact & Recommendation \\
\hline & $\begin{array}{l}\text { Invention } \\
\text { Disclosure, } \\
\text { Legal Services } \\
\text { \& Intellectual } \\
\text { Property }\end{array}$ & $\begin{array}{l}\text { To avoid legal ramifications of use } \\
\text { of the mobile apps a general Battelle } \\
\text { and DOE legal disclaimer is } \\
\text { required to be displayed within the } \\
\text { app. } \\
\text { In order to make the apps available } \\
\text { in the Google and Apple App } \\
\text { Stores, each team was required to } \\
\text { fill out an Invention Disclosure } \\
\text { Report. After meeting with the } \\
\text { Technology Commercialization } \\
\text { staff, they have the lead for } \\
\text { reviewing terms and conditions } \\
\text { associated with each Store. Once } \\
\text { this process is complete, PNNL will } \\
\text { make the apps available for no cost. }\end{array}$ & $\begin{array}{l}\text { Each team and PNNL staff involved in } \\
\text { the app development process are } \\
\text { identified on the Invention Disclosure } \\
\text { Forms. This ensures legal protection for } \\
\text { PNNL, the staff members, and DOE. } \\
\text { Making the apps available for free on the } \\
\text { App Stores provides the general public } \\
\text { with increased health and safety } \\
\text { awareness through mobile devices } \\
\text { developed with tax-payer funding. }\end{array}$ & $\begin{array}{l}\text { Engage the IP Legal Services and } \\
\text { Technology Commercialization staff } \\
\text { early on in the development cycle. } \\
\text { Acquire a general legal disclaimer } \\
\text { from the PNNL IP Legal Services } \\
\text { office. Display the disclaimer in a } \\
\text { conspicuous location within the app } \\
\text { and use bold font, all caps, or another } \\
\text { color. }\end{array}$ \\
\hline $\begin{array}{l}\text { Communications } \\
\text { Management }\end{array}$ & $\begin{array}{l}\text { Maintain } \\
\text { Consistent } \\
\text { Messaging }\end{array}$ & $\begin{array}{l}\text { Organizational messages were not } \\
\text { transmitted individually to each } \\
\text { intern, leading to confusion. }\end{array}$ & $\begin{array}{l}\text { Interns were confused about computer } \\
\text { policies, participation in Division level } \\
\text { intern programs, etc. Due to these } \\
\text { inconsistencies, messages were repeated } \\
\text { multiple times. Additionally, the interns } \\
\text { missed networking opportunities and } \\
\text { events with other students in the Division. }\end{array}$ & $\begin{array}{l}\text { Communicate expectations early and } \\
\text { reinforce as often as necessary. } \\
\text { Underline the importance of internal } \\
\text { networking and relate to workplace } \\
\text { expectation of all staff including } \\
\text { interns. }\end{array}$ \\
\hline
\end{tabular}


Table 2. Risks and Issues

Risk or Issue Description

ADC process and ERICA clearance of materials

Forwarding PNNL email to personal email with auto rule.

\section{Comments}

Students lacked knowledge of the ADC and ERICA

processes. These are not part of intern orientation

and the students were easily confused about who to

contact and what to do.

Students assume they can work under the same rules and guidelines at their college/university.
Suggested Resolution

Future competitions should have clear guidelines about who to contact for ADC review and then to pass materials on to group administrator for ERICA processing.

ADCs need to be lined up in advance and have adequate expertise and time available to facilitate review.

Clear dissemination of PNNL policies regarding computer use, data storage, software downloads, etc. including discussion of repercussions if guidelines not followed.

See Risk Management section in Table 1 
Table 3. Software Quality Assurance Process Improvement Recommendations

\begin{tabular}{|c|c|c|}
\hline Team Name & Defect Description & Resolution \\
\hline Android Team, FoodFeed App & $\begin{array}{l}\text { Violations are not consistent across locations. Some cities have very } \\
\text { descriptive violations and other locations it's hard to tell what the } \\
\text { violation is. } \\
\text { Is there a way to tell if the feed is up-to-date? } \\
\text { If search has no results, should a message display this? } \\
\text { How are restaurant search results sorted? Is there a way to filter the } \\
\text { search? } \\
\text { Search terms must match words exactly in the title. Searching "sushi in } \\
\text { Washington" returns no results, but "sushi Washington" does. } \\
\text { Is there a way to browse restaurants instead of entering a search term? } \\
\text { Once you enter a search, the search term disappears. It would be nice to } \\
\text { be able to see what the search term was. } \\
\text { Spelling errors appear with a red underline in recall information. } \\
\text { Should the user see these? } \\
\text { After performing a search in the Restaurants, there is no method to } \\
\text { clear the search or return } \\
\text { When clicking on the Settings button, it always returns to the main } \\
\text { food feed section (News --> All), should it return to the section that } \\
\text { you were on? }\end{array}$ & $\begin{array}{l}\text { Bugs and defects were identified by PNNL } \\
\text { Software Quality Assurance professionals. Each } \\
\text { team met with the QA staff member to resolve the } \\
\text { problems identified. }\end{array}$ \\
\hline iOS Team, FL $\cup U A p p$ & $\begin{array}{l}\text { When you get to the diagnose screen, it is difficult to navigate back to } \\
\text { the Create/Edit screen. The user should be able to navigate to the home } \\
\text { screen from any screen in the app. The swipe left to right action does } \\
\text { not work everytime. } \\
\text { After you save it takes you directly to the Diagnose screen. Seems that } \\
\text { save should just save, and not move the user away from the screen they } \\
\text { are on. Unless that is intended. } \\
\text { If you have the Vaccination Data and Symptoms both displayed, it } \\
\text { difficult to see what Vaccinations are "checked." Same goes for the } \\
\text { Vaccination Information and Report Flu Type, it is difficult to see the } \\
\text { numbers } \\
\text { On the graph, you can scroll through previous days, but there is no way } \\
\text { to get back to the current day } \\
\text { If you are not connected to the Server you get a "Connection Lost" } \\
\text { message. Would it be useful to indicate that you are connected to the } \\
\text { server, possibly in the info/about screen }\end{array}$ & $\begin{array}{l}\text { Bugs and defects were identified by PNNL } \\
\text { Software Quality Assurance professionals. Each } \\
\text { team met with the QA staff member to resolve the } \\
\text { problems identified. }\end{array}$ \\
\hline
\end{tabular}




\begin{tabular}{ll}
\hline Team Name & \multicolumn{1}{c}{ Defect Description } \\
\hline When changing the level of a headache you can get in a state where the \\
Level is 0 by the "indicator" is still on the avatar. \\
Based on the Avatar's perspective, the left and right side should be \\
switched, unless you are indicating it from the perspective of the \\
person using the app. For example, when adding a symptom to the Left \\
Leg, it appears to be added to the Right Leg of the Avatar \\
Symptoms remain recorded overnight on the symptom screen, but the \\
graph reports that there is no data recorded.
\end{tabular}

Table 4. Vendor Management Process Improvement Recommendations

\begin{tabular}{lll}
\hline Vendor & Issue & Resolution \\
\hline N/A & & Comments \\
\hline
\end{tabular}


Table 5. Other Process Improvement Recommendations

\begin{tabular}{|c|c|}
\hline Areas of Exceptional Performance & Areas for Improvement \\
\hline $\begin{array}{l}\text { The PI imparted lessons learned during a previous on-site training session run by SRI } \\
\text { (Stanford Research Institute) that focused on developing innovation. The interns } \\
\text { were provided instruction on how to sell their ideas (focus on need, approach, } \\
\text { benefit, and competitors), how to evaluate their own ideas and the ideas of others } \\
\text { (positive feedback, constructive criticism, approaching ideas from the point of view } \\
\text { of the client), and how to successfully execute on those ideas. The iteration of } \\
\text { concepts and multiple opportunities to present their ideas formally through } \\
\text { PowerPoint and public speaking provided a valuable learning opportunity for the } \\
\text { interns. }\end{array}$ & N/A \\
\hline $\begin{array}{l}\text { Mentorship from other members of the lab not directly related to the project (i.e., } \\
\text { subject matter experts in epidemiology and graphic design) provided the interns with } \\
\text { valuable expertise and networking opportunities. }\end{array}$ & $\begin{array}{l}\text { Seek out additional SMEs to provide broader exposure to user-centered } \\
\text { design and biosurveillance topics and issues. This may specifically } \\
\text { include a veterinarian, microbiologist, and/or environmental health } \\
\text { expert. }\end{array}$ \\
\hline $\begin{array}{l}\text { The competition resulted in a presentation at the } 2^{\text {nd }} \text { International Conference on } \\
\text { Digital Disease Detection in September } 2013 \text {. }\end{array}$ & $\begin{array}{l}\text { This client requires at least three weeks lead time for the approval of any } \\
\text { information that is to be publically disseminated. This timeframe needs } \\
\text { to be built into the PNNL internal clearance processes. Not meeting } \\
\text { client or internal clearance processes jeopardizes the project team's } \\
\text { ability to publish or present on the research project. }\end{array}$ \\
\hline $\begin{array}{l}\text { An official PNNL news release was written and disseminated via the PNNL News } \\
\text { Center on } 22 \text { October } 2013 \text {. The release was picked up by several other publications } \\
\text { including the UPMC Health Security Headlines Newsletter, eSciencenews, } \\
\text { Communications of the ACM, Globalbiodefense.com and many more. Wide } \\
\text { dissemination of the project's mobile app development competition highlights PNNL } \\
\text { as a leader in this research domain. }\end{array}$ & $\mathrm{N} / \mathrm{A}$ \\
\hline
\end{tabular}




\subsection{Judging}

This judging competition offered the teams the opportunity to present the findings of their project: their applications, the benefit to biosurveillance research, and domains where their applications can provide real benefit to mobile device-enabled populations living in developed and developing nations.

The judges in the competition came from a diverse range of expertise, including high school age students, teachers, parents, epidemiology experts, public health experts, technology experts, and others. Each was selected for their unique background and experience, and all judged the teams based on the same criteria. See Appendix E (page 25) for a list of all judges and their affiliations.

\subsection{Judging Criteria}

Judges were asked to complete a score sheet detailing the positives and negatives of each team's app. The criteria were developed based on adapting criteria from similar competitions to the unique aspects of this particular competition and domain area (see Appendix E). There were four parts of the criteria:

1. Perceived Value and Importance for Health Situational Awareness

2. Originality and Innovation

3. Quality of User Experience (User Interface and Presentation)

4. Long Term Value and Sustainability

The judges were asked to rate how well the app approached each criterion on a scale from Excellent (4 points) to Poor (1 point). In the end, the scores from each judge were accumulated and averaged to determine a winner. Additionally, a discussion was held after the presentations to talk through any discussion points that the judges wished to discuss before announcing a winner. See Appendix E for sample score cards.

Table 6. Judges Feedback for the Android Team App, FoodFeed

\begin{tabular}{l} 
Perceived Strengths \\
\hline Good that listed data sources (e.g., USDA, twitter feeds) and that there is a clearly stated path of where the info \\
goes. Clear means of health situational awareness with self-reporting feature \\
Very beneficial to the public by reporting risks, providing access to health reports about restaurants. \\
The information available from the application is useful and educational \\
The app provides an easy way for users to stay aware with minimal interaction and encouraged them to contribute. \\
Because this app combines so much food-borne illness related information, into an unmatched and useful format, \\
the benefit to public awareness is very clear. \\
Love having all the information together in one app, especially up to date recall information and restaurant \\
inspections. \\
Good compilation of reports, recalls, information - easy to use to help avoid food-borne illness. Over time pulling \\
together may allow more use of data. \\
As long as it has the users it has high potential to gain and maintain health situational awareness. \\
Tying health reporting to services useful to increase reporting of food-borne illness. Great potential. \\
People would use two app for checking restaurants and possibly for other food topics. A link to the local / state \\
health department is good.
\end{tabular}




\section{Perceived Strengths (cont)}

Good interaction of variety of information into a single app. Simplifies information found by the user. Although public health community would not use this data alone in identifying and investigating food-borne disease, it does provide a new way to obtain notification of potential cases needing investigation.

Foodborne illness is an underserved area of public health \& surveillance. Value proposition is around aggregating and organizing existing public feeds of FB data--great!

Great start to an app that brought together disparate data into a nice package.

This app provides a means of crowd-sourcing food-borne outbreak data from mobile devices. It provides a quick means of determining potential outbreak events. The group provided a very clear statement of the need the app attempts to fill.

Clearly demonstrates how the info can be shared. Did a good job of explaining why this app is unique.

This app has so much info about food safety. It's not just what has been recalled, but how to prepare/store certain foods prone to illness.

There's nothing radically different about the application, but it does everything very well.

The originality of the idea has been tried on traditional websites, but it fails in the innovation where this app succeeds.

The app uniquely combines a lot of useful information in one place in a presentable fashion. The fact that it seems a lot like yelp is the only detractor, from originality.

Very current topic. Food safety applies to everyone and having an easy to use app in the hands of consumers could conceivably have a big health influence.

Wanted to see something like this for some time. Similar apps are not available.

Combines useful features of multiple apps into a single app. Adds data on restaurant inspections.

Comparison with potential competitors was very good; there doesn't seem to be an existing app like it, again it's an underserved area, so innovation is good.

This is an innovative fusion of many content sources, and including the reporting of symptoms is very unique. The idea has a clear draw to people concerned about health.

Easy to use app. Like that the data can be filtered. Output and visualization are understandable.

Enjoyed using this app, and it was very easy to navigate and understand.

Very easy to use. Reporting an illness was simple.

Excellent. Not only is it great looking, but their situations seem very well thought out. There is obvious immediate benefit to the user to keep them coming back, and notifications keep the required interactions to a minimum.

Nice, clean interface, appeal to a wide age range, and background.

UI easy to use

Very polished appearance. Clear layout of information.

The design was clean, uncluttered, looked good. The user experience is perhaps less ambitious than the FLU avatar system, but worked well.

Overall, it looked very good for this level of effort.

There are some apps out there with similar capabilities that are already popular with the public, but I really like this particular app.

The focus on informing and educating users was evident in each feature of the app. Excellent presentation.

The more sources the more valuable this app becomes. All of that can happen behind the scenes. User get great benefit from not a lot of effort.

Would definitely make use of this app. It has many similarities to yelp, and speaking to its sustainability in the market it's targeting.

Very useful with a broad consumer base

Easy way to report to local health department

Greatest value is the combining of info from other sources, rather than reporting has great potential given that users always need to eat.

\section{Perceived Weaknesses}

From presentation, said use a type of programming that allowed for further long-term development. Indicates 
looking to the future. May be challenging to encourage folks to keep using (one hit wonder effect). Did address why people will want to keep using them - this was answered in the question period.

Decent base for a startup, though creativity in the funding model would be required. Greatest concern is the number of users. Simply put, it is incredibly difficult to build a user base, even if you have a great idea and a great app. Thus if there is some way to integrate with some system that already has a large user base -- Facebook and Yelp were just examples; there are many -- that can improve your chances a lot. In short, if you try to go it alone I think you can be almost guaranteed failure. One other thing to be sure of is that your scraping activity does not violate use agreements on the target websites.

Seems like this might keep users coming back because different foods are always in the news as being contaminants.

\section{Suggestions for Improvement}

The team may be further benefited by a usability requirements document, with personas? Tools such as cognitive walkthrough and heuristic evaluation may be useful as well.

In its current form, the tool doesn't have any data or visualizations to share with health departments. Much like FL*U, this tool seems to provide situational awareness to the user but not to the public health/population level. How is this adaptable to other uses? Perhaps user ratings to help identify reliable sources?

Little innovation

It's a straightforward, well-executed solution to a gap. However, it wasn't obvious to me how it made "innovative usage of the mobile platform." What are the benefits of it being an app rather than a website (which would also be available on mobile devices)?

This approach has been developed for similar problem sets such as medicine reporting (e.g., MedWatcher). It would be interesting to link to yelp or OpenTable. This likely goes beyond this effort but just a thought. It was clear that they have discussed Yelp's efforts in this area.

There were very minor UI or UX concerns.

The interface is intuitive and easily navigable. The interface design is utilitarian, and suits the purpose of this app, but may make it difficult to market since it's not attention grabbing.

Easy to use and highly informative. Very text heavy. Would have liked more graphics.

Good user interface, but a personal data base would be nice such as past experience.

Could use better visualization regarding non-trivial insights. Summary of illness in area in part three days or links to data on confirmed cases. Might be useful for analysis.

If the team continues, there's plenty of polish to do

Difficult to determine the user experience from the presentation.

Seemed pretty smooth, but couldn't tell if the users could navigate the screens in an order they prefer or if they had to go through the screens in the path shown. For example, what if a user wants to start with symptoms or venue rather than foods?

Out of the gate, this app is ready to provide users with info that is relevant to them. The long term issue may be in the data gathering and getting more sources to participate.

Ability to report illness on mobile platform is useful, but not sure how it is tied to correct local health jurisdiction.

Closing the loop by making user reports available to users, visualized, etc., is still missing. But options for sustainability are greater given that it's fed by public data, as opposed to relying simply on user submissions. This is a potentially valuable resource to allow crowd sourcing food-borne outbreak information. People will be motivated to report. However, not clear people will go to a specific app for this. Regardless, those that will be interested it looks like they would consistently report and use. The MedWatcher experience would be a good analogue to see how much participation one could expect from such an app.

Don't quite understand how the system would be sustained (from an infrastructure standpoint) over the long run. 
Table 7. Judges Feedback for iOS Team App, FL $\bullet U$

\begin{tabular}{l} 
Perceived Strengths \\
\hline Ability to use to record in $3^{\text {rd }}$ world countries could be helpful. OTC medicine usage could be helpful. \\
The tracking of symptoms and ability to see historical personal data is very useful. Broader applications than flu. \\
Also like access to real time flu epidemiology. \\
Combines useful features of multiple existing apps into a single app. \\
Like the avatars and level of customization available to the user. Easy to use app with help buttons to find categories \\
easily. \\
From what was seen in the video presentation the interface looked amazing simple and easy to manipulate. Using \\
avatars is a fun approach to make the data entry process more personable and unique. Most of the graphical \\
representations made sense. \\
Beyond avatar, didn't see the difference beyond existing apps. However, use of personal health diary at physician's \\
office has potential to improve information exchange. \\
This app has a lot of potential and the interface was very easy to work with. \\
Perceived Weaknesses
\end{tabular}

Perceived Weaknesses

Easy to use with good potential but the reliance on user input could be a roadblock as well. They use for doctors in $3^{\text {rd }}$ world countries does sound good.

There are some issues with ease of use, and whether or not this app is as useful as it was meant to be.

Good job of setting up justification for the app. However, if folks are really ill, will they use it? The app is easy to use, but the only data is google flu. Suggest adding other data streams.

This type of system can be useful for both engaging the public AND generating a faster signal of flu activity. Big weakness is user uptake--if people don't use it on a large scale, there will be no data.

The key issue is motivation. Would people actually use it, consistently over time, and in sufficient numbers to provide useful data? Not convinced that the team understood human motivation well enough, nor the use cases that apply to real people. That is, the claim of "engaging" is not supported. Suggest focusing less on features and more on motivation and use cases. Is there a usability requirements document, with personas? Tools such as cognitive walkthrough and heuristic evaluation may be useful as well.

The tool seems to be great to provide situational awareness to the individual, and to the individual's health care provider. Not sure about the value for public health/population level situational awareness. This is a challenge because we can't know that people who don't report aren't sick (i.e. how do we know the baseline of healthy to see if there is actually an increase in an area). Would the spikes be a result of a change in marketing for a given week, or another illness that has similar symptoms? High fear of false negatives or positives from a PH decision maker.

The idea was there. It just needs some hooks to allow the user to want to come back and use it.

The use of gaming the experience is good, but I think lacks enough actual game elements to attract users.

The app is original for self-reporting, but so narrowly forgets the age group. Other groups eg. Elderly

The app is original for self-reporting, but so narrowly targets the one age group. Other age groups (eg. Elderly) may be a more tolerant target population or at least good to include them as well as others.

Need to be able to provide or indicate symptom duration. UI functional but could use some more polish. Avatar use is creative.

Nice interface, easy to use. Need for more info for user to benefit from.

Related to the motivation concerns, the app's user experience seemed poorly connected to actual use cases and scenarios. It is possible that the avatar model and other interactions are the best approach for the target audience, but I didn't see any evidence for this.

Well done interaction, wonder how well people will like having to do the scale (1-10) for each symptom. I think the avatar is a great experience for younger users, but unclear if that would be seen as "cool" or "fun" when the app starts to get marketed to other population segments. 


\section{Perceived Weaknesses (cont)}

Will increase in usefulness as the user base grows. Uncertain market response. Good potential for expansion to other diseases but will require significant modification. Provides minor innovation over existing apps. With users only using the app when they have symptoms, may be difficult to gain large user base. Points or badges for using may increase the user base.

Requires constant interaction to gather accurate info, and critical mass to get enough. But the benefit to the user is intangible and unlikely to encourage that level of involvement.

It will be difficult to see how to validate these data. The subjectivity of scaling the data will be problematic and therefore challenging for public health professionals to trust these data. Confirming cases to the flu type will be very noisy. Future effort should focus on influenza like illness and not worry about typing because folks won't know if it is $\mathrm{h} 1 \mathrm{n} 1$ or $\mathrm{h} 7 \mathrm{n} 9$. Normalizing the self-reporting data will be challenging (1-10 scale).

Not sure the team's plan for how to sustain the system (IT infrastructure) or how to keep the users engaged over the long term.

\section{Suggestions for Improvement}

Limited benefit to public health community outside of reporting of symptoms for flu-like illnesses. With a large enough user base, could be useful. Not likely to be used as an official reporting source. Could be very useful to the public for situational awareness but FluNearYou does that already.

Maybe not for a market of a "Health App", don't believe people that are ill will want to set up an avatar. Instead, get them while they're healthy and then have the avatar reflect their symptoms.

Unclear if reported data is user symptoms, which has advantage of "early warning" or only confirmed diagnosis, which is accurate but not timely.

There's immediate benefit to public awareness in terms of combining the google flu data with personal flu. However, the surface impact to public health appears minimal, but it seems like a huge potential for a mechanical turk type process.

Since this is self-reported, the data confidence may be low. Maybe make this a more triage type app.

The map provides a nice overview of the reported data, but unless the user is a real health junkie they may not use the app often

The presenters could provide a more compelling description of the need and how their solution fills an existing gap among many different attempts at influenza surveillance.

Avatar may increase user enjoyment and interaction but probably need to tie it to a social network to get user value.

Nice comparison with other apps. What is benefit to user - how do they know flu outbreak is in the area?

It combines many existing tools and ideas. Had the Mechanical Turk process been suggested, as a user incentive, I feel this would perform better.

I'm involved with Flu Near You, so again biased, but also aware of the competition. Mainly, three features they call out as not present in FNY, avatars, diary, and a HeatMap. First, FNY has HeatMaps available on the Web site.

Second, it's not clear that avatars and the diary feature will be a difference maker for user participation.

The self-reporting aspect of the app is not overly novel; however, the attempt to "gamify" self-reporting is novel.

The Avatar data input is a fun and interesting approach to allow for potentially greater language agnostic input.

Like the idea of riffing off the tamagotchi concept to incentivize involvement. Gamifying is a relatively untapped area of incentivizing involvement. This is a good step that attempts towards gamifying. Long-term involvement in the app remains an issue but it sounded as if the team had some ideas to develop further.

Did not feel this was a huge change as compared to existing tools (especially Flu Near You)

Requires too much time to enter symptoms - use of range doesn't seem to add value. If users won't use it, it doesn't add value.

The layout and appearance of the app is very appealing as well as the navigation, although at times the buttons do not react to user input.

The interface was simple and engaging. Colors for the density map were not intuitive.

While visually appealing, the navigation between the core parts are rough. Not sure that this UX would be suitable to casual smartphone users.

The use of almost entirely custom UI elements with a lack of feedback and guided navigation makes it difficult for new users. There's not a lot of immediate benefit. 


\section{Suggestions for Improvement (cont)}

The app is just a little confusing to navigate and figure out how to use.

Clearly a lot of work went into the avatar development, and it's actually pretty cool. Otherwise there are a few rough edges in the graphic design.

Make it a yearly-round app for health and have it look more or less vital based on your data.

Expandable to other diseases would be good.

Flu is only a problem several months out of the year. Would like to see this as a personal health tracking app rather than specifically flu.

Would not use the app in its current form.

You would really need this app to be on a user's device long enough before they would ever need it and have them consistently go back and use it.

Suggested improvements would be essential: dropping off symptoms, suggesting medical attention. The plan for using with other outbreaks is good.

Suggestion for long term value and travel info (recent travel to infected areas). Good that they're looking to expand to additional languages.

There is potential for long-term value with high participation, but not clear how that will be achieved or sustained. The guidelines essentially ask, have the presenters "convince[d] the judges that ... [the] app that a variety of realworld users would use?" Unfortunately, I'm not convinced, for the reasons noted in more detail above. 


\section{Appendices}

The following appendices contain these documents and information:

- Appendix A: Job Requisition

- Appendix B: Flyer Advertisement

- Appendix C: Email Recruitment Template

- Appendix D: Email Recruitment Distribution List

- Appendix E: Competition Judging Flyers (5)

- Competition Judging Event Overview

- Student Team Bios

- Judges Panel

- Judging Criteria

- Judging Score Cards 


\title{
Appendix A: Job Requisition
}

\author{
Job Requisition Details \\ Job ID: 302340 (Undergraduate), 302341 (Master's) \\ Directorate: National Security \\ Division: Computational \& Statistical Analytics
}

\section{Job Description}

The Computational and Statistical Analytics Division at Pacific Northwest National Laboratory focuses on advancing computational and statistical foundations to deliver algorithms, information and scientific data management, visualization and analytics, data intensive information systems, distributed data processing pipelines and environments, and secure computing infrastructure to enable next-generation heterogeneous computing for scientific discovery, situational awareness, decision support, and predictive modeling.

This internship will offer candidates the opportunity to explore research career options and/or conduct thesis/dissertation research to gain practical training in computer science and engineering.

Research will be conducted in close collaboration and under the guidance PNNL scientists and engineers, and will include one or more of the applied disciplines above.

PNNL will host an intern mobile app competition to foster novel and creative approaches that leverage mobile devices for enhanced biosurveillance. Each team will target an iOS, or Android, or Windows Phone device. Intern teams will be responsible for identifying the target user, usage scenarios, and app design. Interns will be encouraged to leverage and adapt new and existing algorithms, analytics, mathematical and other tools and methods to support the analytic needs of the target users. Final tools will enable users to define expected and known relationships between multiple sources of information. The apps may enable a range of investigations, from forensics to time series event detection, to control option assessment and what-if scenario analysis. The mobile app competition will be managed to provide both a positive educational experience for the interns as well as high-quality output.

PNNL will organize and provide support and guidance for a solid design and implementation process. Teams will be chosen to contain a suitable representation of experience, including mobile development, software engineering, human-computer interaction, social media, epidemiology, and mathematical modeling and simulation. Additionally, interns will exhibit a strong desire to work collaboratively in a team and the ability to effectively communicate and present their ideas. 


\section{Minimum Requirements}

Candidates must be matriculated/enrolled in an Undergraduate or Master's program at an accredited college or university. Minimum GPA of 3.0 is required. All staff at the Pacific Northwest National Laboratory must be able to demonstrate the legal right to work in the United States.

\section{Qualifications}

Applicants with experience in one or more of these areas, or closely related topics, are encouraged to apply:

- Android app development

- iOS app development

- Windows Phone 8

- Social Media Analytics

- Epidemiology

In addition to the above skills, experience with the following would be beneficial:

- Natural language processing

- Human-Computer Interaction, interface development, or graphic design

- Web 2.0 technologies

- Information synthesis

- Data fusion

- Tools and methods for mobile collaboration

- Mathematical and statistical methods for information analysis and knowledge discovery

- Python, Perl, or algorithm development. 


\section{Appendix B: Flyer Advertisement}

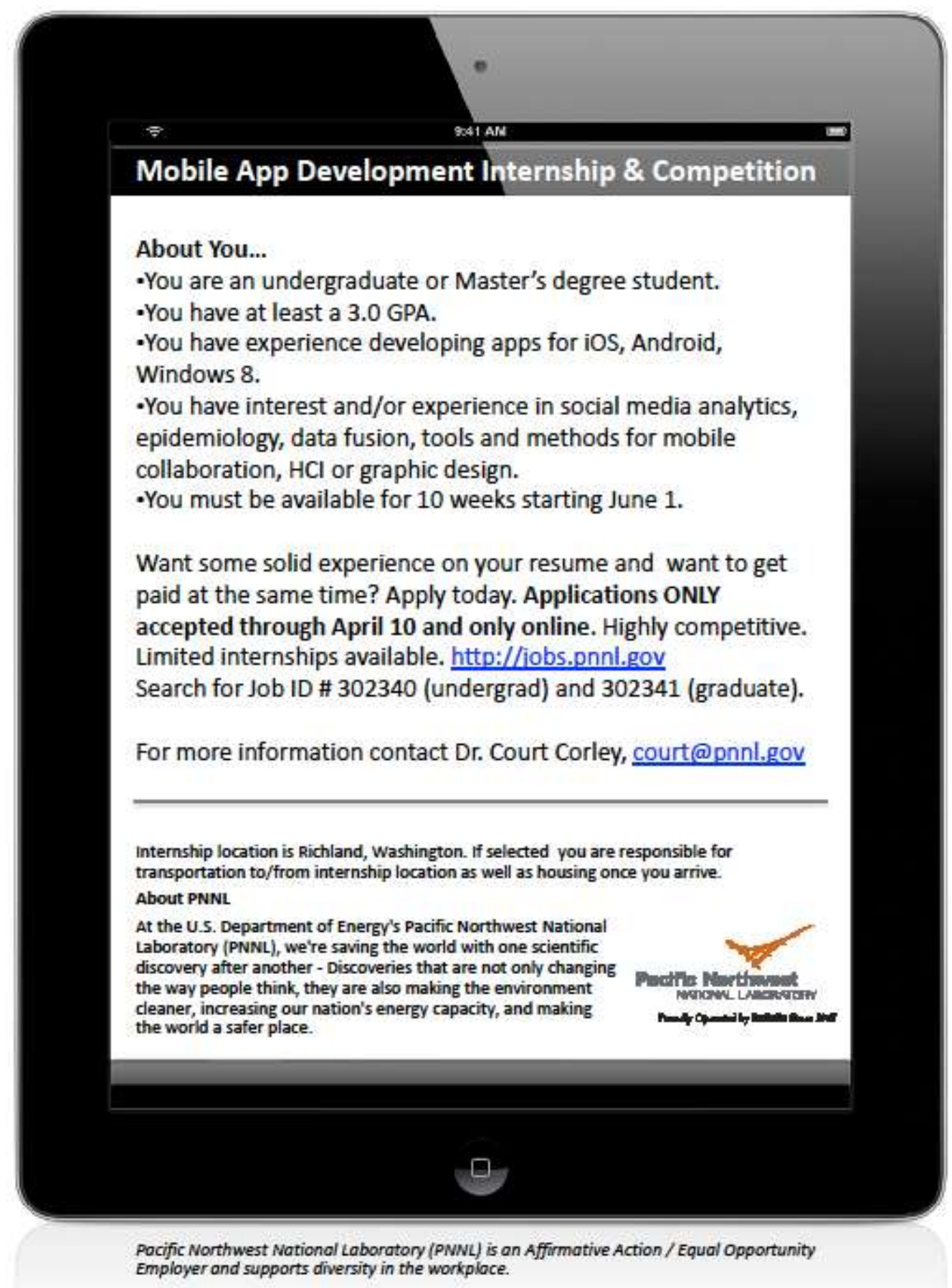




\title{
Appendix C: Email Recruitment Template
}

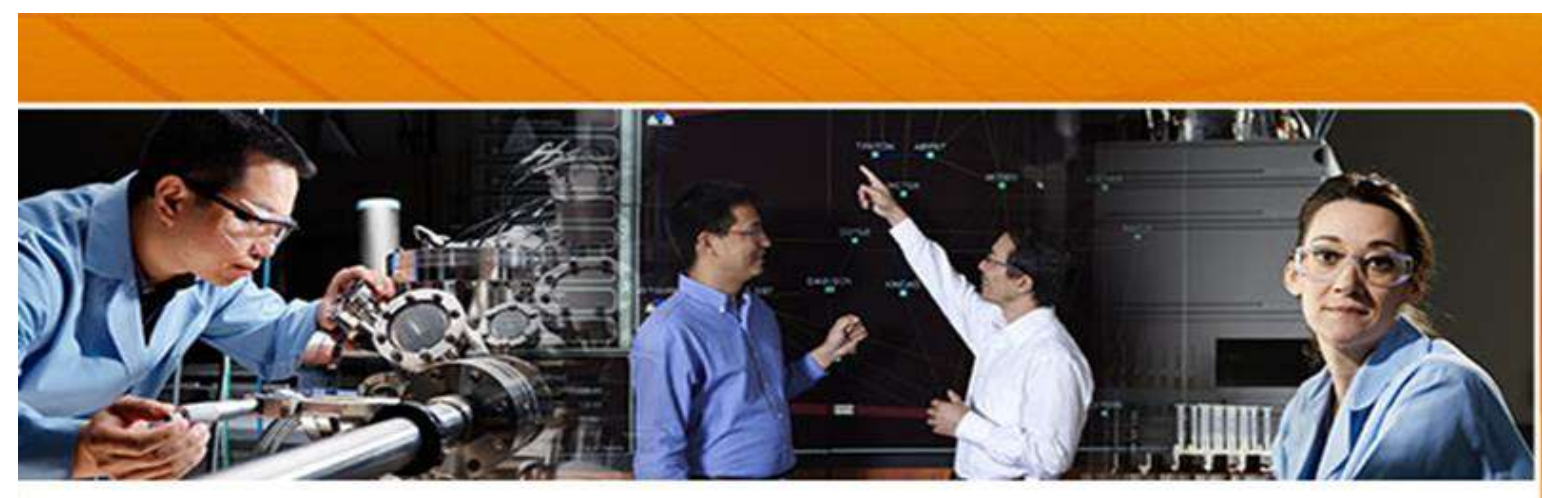

\section{Mobile App Development Internship \& Competition}

\author{
About You... \\ - You are an undergraduate or Master's degree student. \\ - You have at least a 3.0 GPA. \\ - You have experience developing apps for iOS, Android, Windows 8. \\ - You have interest and/or experience in social media analytics, epidemiology, data fusion, \\ tools and methods for mobile collaboration, $\mathrm{HCl}$ or graphic design. \\ - You must be available for 10 weeks starting June 1.
}

Want some solid experience on your resume and want to get paid at the same time? Apply today. Applications ONLY accepted through April 15 and only online. Highly competitive.

Limited spaces available. http://jobs.pnnl.gov

Search for Job ID \# 302340 (undergrad) and 302341 (graduate).

For more information contact Dr. Court Corley, court@pnnl.gov

Internship location is Richland, Washington. If selected, you are responsible for transportation to/from internship location as well as housing once you arrive.

\section{About PNNL}

Interdisciplinary teams at Pacific Northwest National Laboratory address many of America's most pressing issues in energy, the environment and national security through advances in basic and applied science. PNNL employs 4,500 staff, has an annual budget of nearly \$1 billion, and has been managed for the U.S. Department of Energy by Ohio-based Battelle since the laboratory's inception in 1965. For more information, visit the PNNL News Center, or follow PNNL on Facebook, Linkedln and Twitter.

Pacific Northwest National Laboratory (PNNL) is an Affirmative Action / Equal Opportunity Employer and supports diversity in the workplace.

JOIN US IN PUTTING DISCOVERY INTO ACTION.

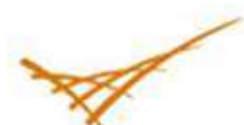

Pacific Northwest NATIONAL LABORATORY

Proudly Operated by Batlelle Since 1965 


\section{Appendix D: Email Recruitment Distribution List}

Flyers and information advertising the mobile app development competition were distributed to the following lists, schools and agencies:

- iPro Jobs (UW Ischool)

- LITA

- DigLib

- Asis-L

- Harvard

- Carnegie Mellon

- College of Charleston

- University of Wisconsin-Milwaukee

- Ball State University

- DeAnza College

- Columbia Basin College

- Georgetown CS Dept.

- Purdue CS Dept.

- Washington State University EE/CS Dept.

- University of North Texas

- Global Health Forum

- Health Informatics World Google group

- International Society for Disease Surveillance

- National Institutes of Health

- Other select government agencies 


\title{
Appendix E: Competition Judging Flyers
}

\section{Biosurveillance Mobile App Development Competition}

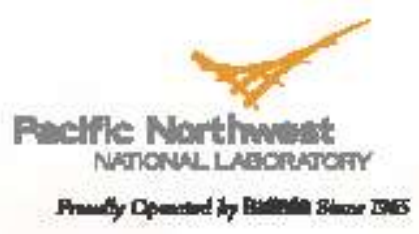

\author{
When: Monday, August 19, 2013 - 12:00 to 2:00 pm Pacific \\ Where: PNNL Campus (CSF/Darwin Rm. 1007 or Online via Lync)
}

Mobile devices are an enabling technology providing access to health care information and resources, safety and security information, social media and other interactive technologies. These technologies are ideal for addressing the needs of digital disease detection. To explore solutions to biosurveillance challenges Pacific Northwest National Laboratory (PNNL) has partnered with the United States Government Biosurveillance Ecosystem program to host a mobile application contest featuring teams of student researchers interested in addressing these problems. Each team was carefully selected to bring together students interested in the design and development of socially beneficial mobile applications that could be used to meet the needs of bicsurveillance practice. The students have been given broad flexibility in terms of the types of applications they can develop, and have been given access to scientists and researchers at PNNL who have domain-specific knowledge to guide them. The aim of the intern competition is to provide support for innovative research in biosurveillance, as well as motivating and inspiring the next generation of researchers who will be at the forefront of investigating these problems.

One team has focused on the Android platform and is developing a food safety app, FoodFeed. FoodFeed combines recall information, outbreak alerts, and restaurant inspection data to help users make informed food choices. Users can report suspected cases of food poisoning and get information about the risks associated with each food.
The user interface includes a newsfeed, sharing to social networks, and a modern design.

The other team is focusing on the iOS platform and is developing a multi-national influenza surveillance and disease prevention app targeted at teenagers, $F L \cup U, F[\bullet U$ is user-driven and inspired by the concept of Tamagotchi, FL・U allows user to create one or more customized avatars. The avatars will show various symptoms and reactively according to userinteraction. For example, if user reported that he or she has a fever with 101 degrees $F$, the avatar's face will turn to red. The app is targeted towards teenagers in the US and China through bi-lingual interfaces. Other features include vaccination notification, accurate flu-case map and individual health index record displayed intuitively through an info-graphic.

This judging competition will present the findings of the student teams: their applications, the benefit to biosurveillance research, and domains where their applications can provide real benefit to mobile deviceenabled populations living in developing nations.

\section{For additional information contact:}

\section{Dr. Courtney D. Corley}

courtepnni.gov

$(509) 375-2326$

August 2013 | PNNLSA:97744

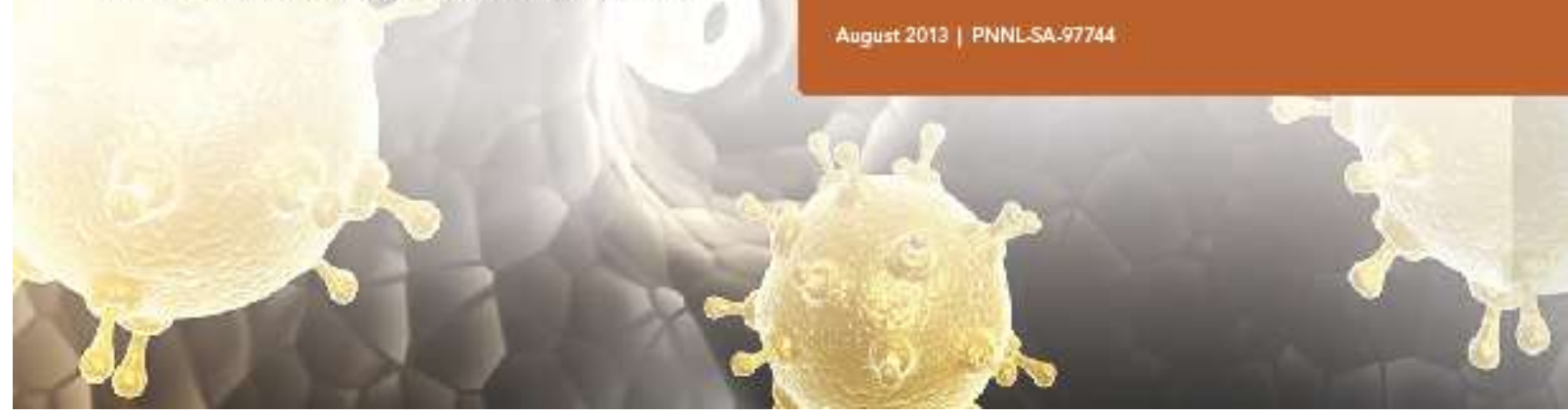




\section{Biosurveillance Mobile App Development Competition}

Rocifle Northos NATONLL LAECRATOFY

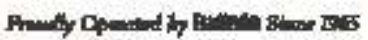

\section{STUDENT TEAMS}

\section{Android}

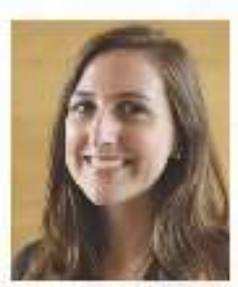

Maria Antoniak

School: University of Washington

Degree Program: Master of

Science, Computational Linguistics

Hometown: Richland, Washington

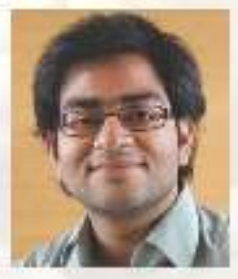

Mohit Bhalla

School: Syracuse University, L.C. Smith College of Engineering and Computer Science

Degree Program: Master of Science

Program in Computer Science

Engineering, Software Systems

Hometown: New Delhi, India

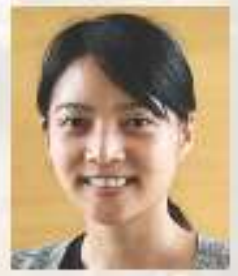

Lily (Fing Hsin) Chou

School: University of Southem California

Degree Program: Master of Fine Arts, Interactive Media

Hometown: Taipei, Taiwan

Janani Sub biah

School: Arizona State University

Degree Program: Master's in

Engineering, Computer Science

Hometown: Chennai, India

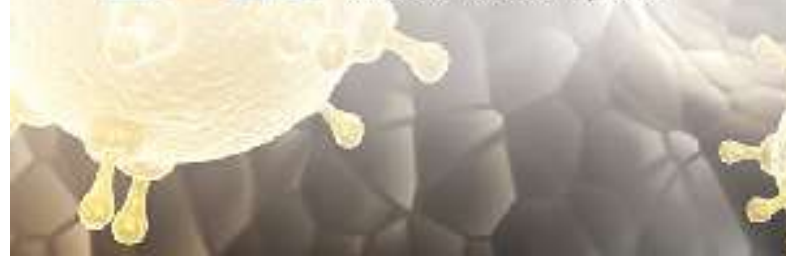

iOS

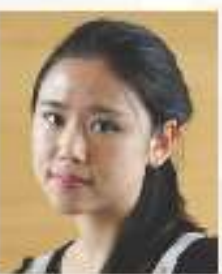

Cheng Yang

School: Carnegie Mellon University Degree Program: Master of Entertainment Technology/School of Computer Science

Hometown: Hunan, China

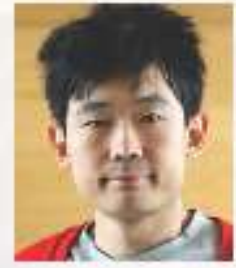

Melo (Langquan) Oiao

School: Dartmouth College

Degree Program: Master of Science, Computer Science

Hometown: Qingdao, China

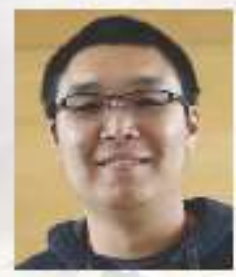

Yudong Zhang

School: Rensselaer Polytechnic Institute

Degree Program: Master of Science, Information Technology \& Web Science

Hometown: Beijing, China

For additional information contact:

Dr. Courtney D. Corley

courtopnil.gov

$\{509\} 375-2326$

August 20131 PNNLLSA.97748 


\section{Biosurveillance Mobile App Development Competition JUDGES PANEL}

Rocifle Northowat NATRONLLLAECRATCFY

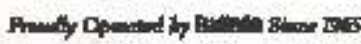

Epidemiology \& Microbiology

Rachel Bartholomew, Pacific Northwest National Laboratory

Dylan George, U.S. Dept of Health \& Human Services Mary Lancaster, Pacific Northwest National Laboratory

Infectious Disease Surveillance Kelly Bennett, U.S. Dept of Health \& Human Services Helen Cui, Los Alamos National Laboratory

Digital Disease Detection

Clark Freifeld, Harvard

Jennifer Olsen, Skoll Global Threats Fund

Mobile Development

Jeff Boyus, Pacific Northwest National Laboratory

Geoff Elliott, Pacific Northwest National Laboratory

Local \& Community Health

Amy Person, Benton-Franklin Health District

Susan Shelton, Benton-Franklin Health District

Biodefense \& Global Security

Ann Lesperance, Pacific Northwest National Laboratory

Astrid Lewis, U.S. Dept. of State

Nancy Nurthern, U.S. Defense Threat

Reduction Agency

Dick Weller, Pacific Northwest National Laboratory

\section{End-Users}

Emily Blankingship, Teacher, Delta High School

Chase Dowling, Pacific Northwest

National Laboratory

Donna Doyle, Mom

Katelyn Doyle, Teenager, Delta High Schood Dylan Mockler, Teenager, Delta High Schood Ann Wright-Mockler, Mom \& Science Educator, Pacific Northwest National Laboratory
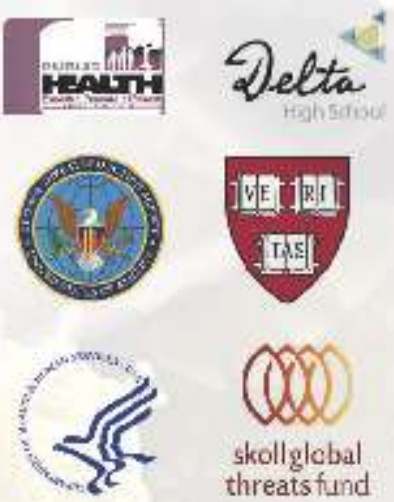

skollglobal threatsfund
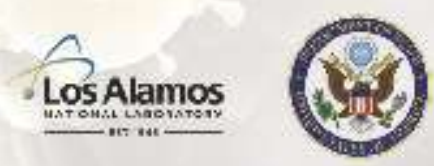

For additional information contact:

Dr. Courtney D. Corley

courtepinilgov

(509)375-2326

Auguet 2013 | PNNLLSA-97741
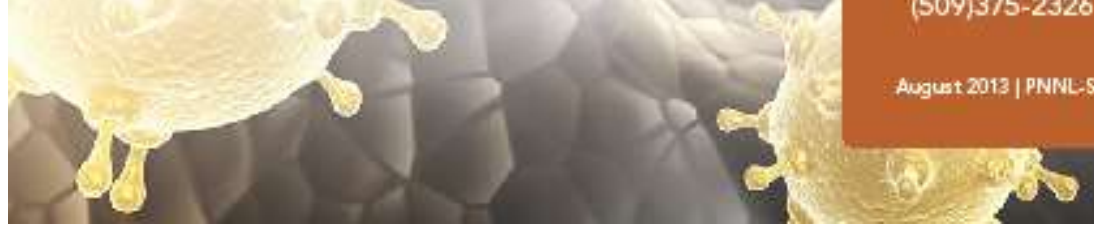


\section{Biosurveillance Mobile App Development Competition JUDGING CRITERIA}

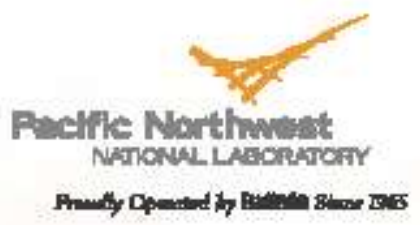

Please review each entry based on the categories below. Enter the point value and any additional observations or comments on the accompanying score cards (below).

1. Perceived Value \& Importance for health situational awareness: The first step in building a great mobile application is identifying the need you seek to meet with your application. This could be a problem you wish to solve, a task your application will help mobile users do, or maybe a better, faster way to accomplish something for the people on the ga. A successful application will meet an important need and may be part of a sustainable enterprise. Items that should be considered when rating this category are: whether the application is easier and more effective than manually browsing web and social media, whether the data and visualizations it delivers adds to public health situational awareness, and whether the insight it supplies is useful to the end user.

Excellent: The submission has a high potential to gain/maintain health situational awareness. The application is extremely easy to use and provides comprehensive, effective and useful output data. (4 points)

Good: The submission has potential to gain/ maintain health situational awareness. The application is easy to use and/or provides effective and useful output data. ( 3 points)

Fair: The submission may gain/maintain health situational awareness, but has issues with either ease of use or with the usefulness of the output data. (2 points)

Poor: The submission does not add any ability to gain/maintain health situational awareness beyond what currently exists for citizens and public health practitioners. (1 point)
2. Originality \& Innovation: How unique and original is your application idea? How well does the application compete against any competitors? How does the application make innovative usage of the mobile platform to meet users' needs? Beyond the basics, each entry will be rated to the degree of new thinking it brings to applications targeting health situational awareness. Innovations that help refine the tool's output or add additional knowledge are encouraged. These innovations may include but are not limited to: adaptability to categories beyond diseases, reduction of noise to improve data quality, refinement of geolocation ability, improved filtering, validation, etc.

Excellent: The submission meets and exceeds the basic requirements by adding significant and/or novel innovation to improve the knowledge gained in the output data. (4 points)

Good: The submission meets the basic requirements and adds some additional innovation to improve the knowledge gained in the output data. ( 3 points)

Fair: The submission meets the basic requirements but does not add any additional innovation. (2 points)

Poon The submission fails to meet the basic requirements. (1 point) 


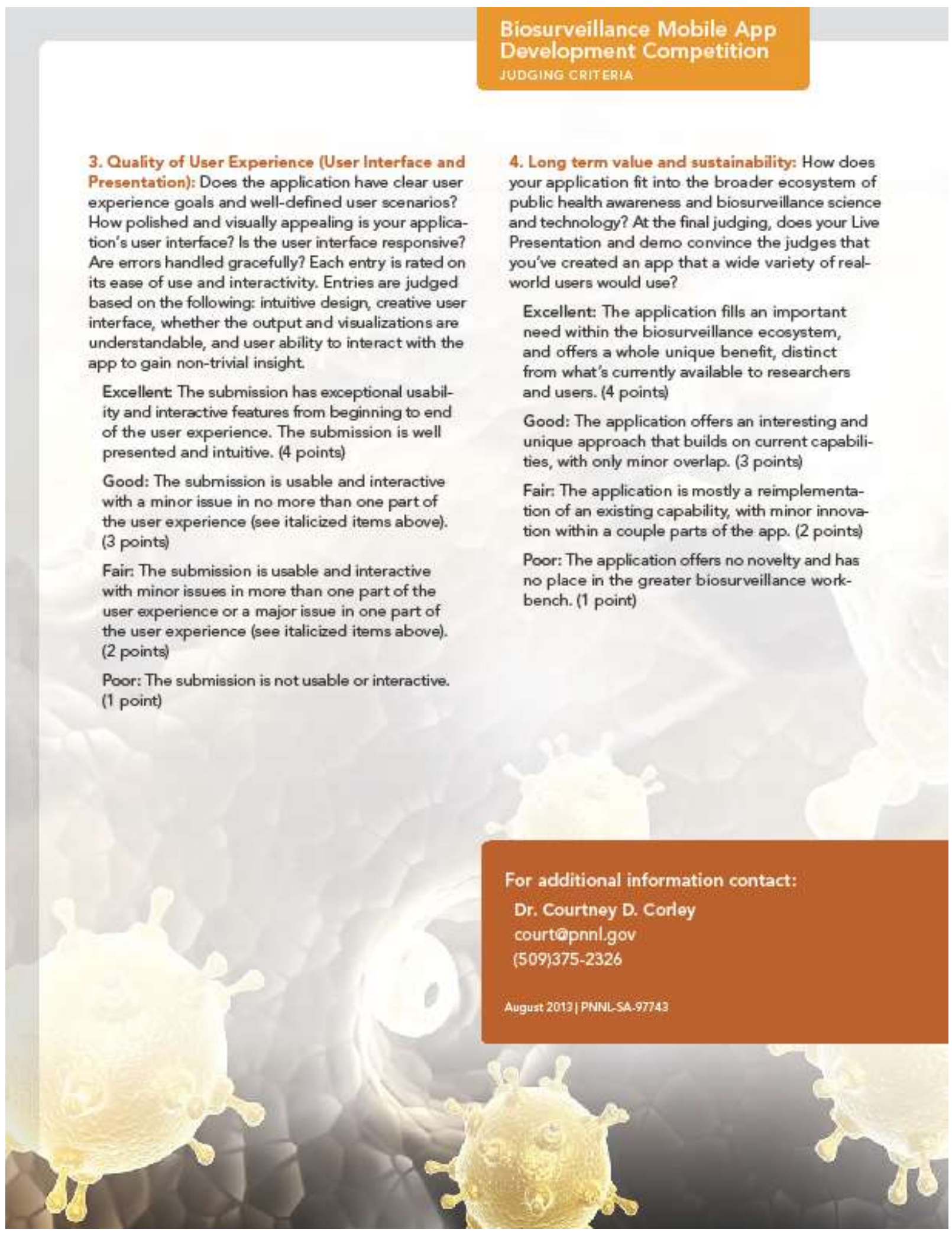




\section{Biosurveillance Mobile App Development Competition \\ SCORE CARD \#1}

Rocifle Northost NATKONLLLAECRATCFY

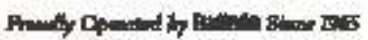

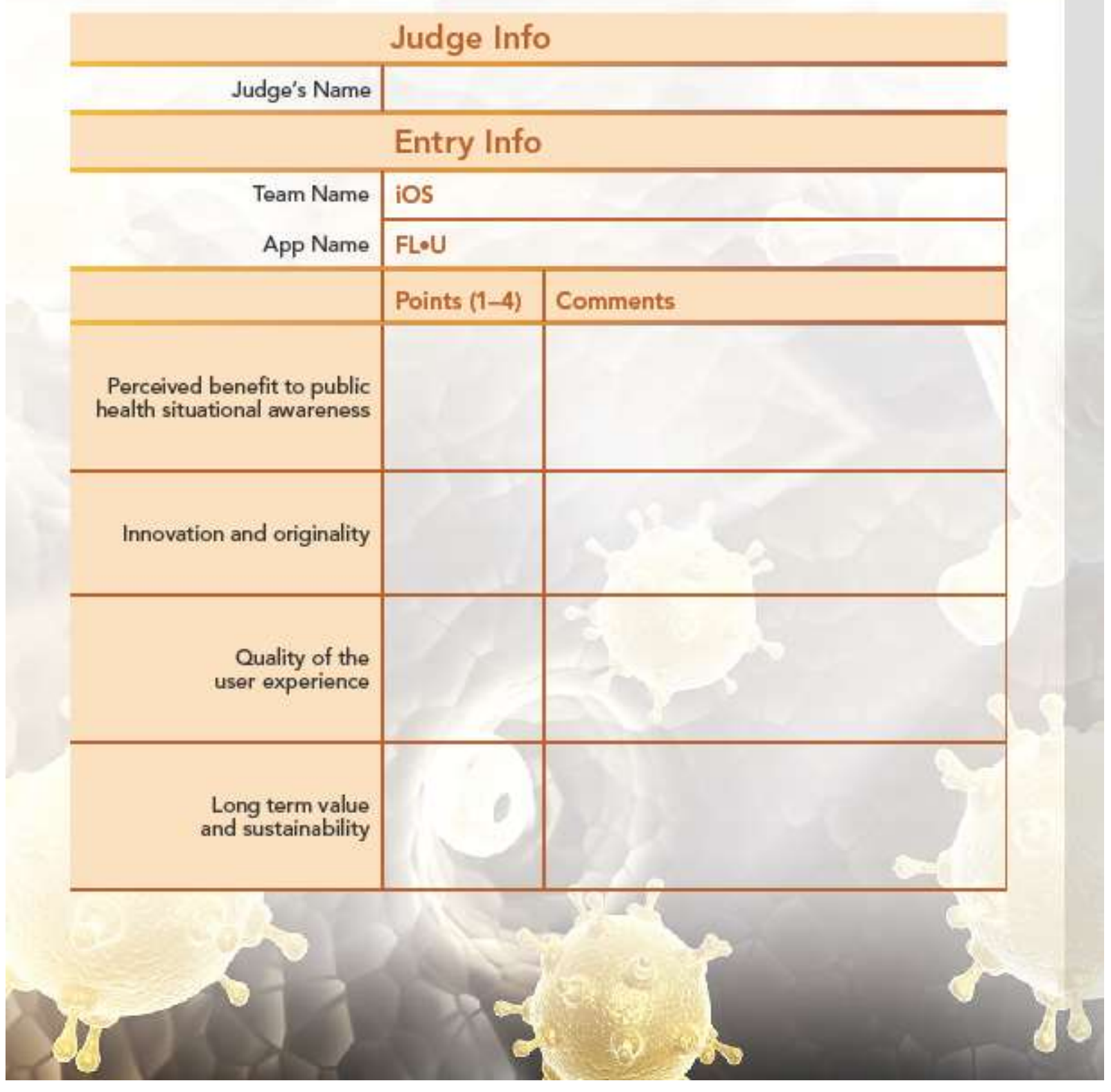




\section{Biosurveillance Mobile App Development Competition \\ SCORE CARD \#2}

Ruclife Northnest NATKONLLLAECRATCFY

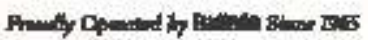

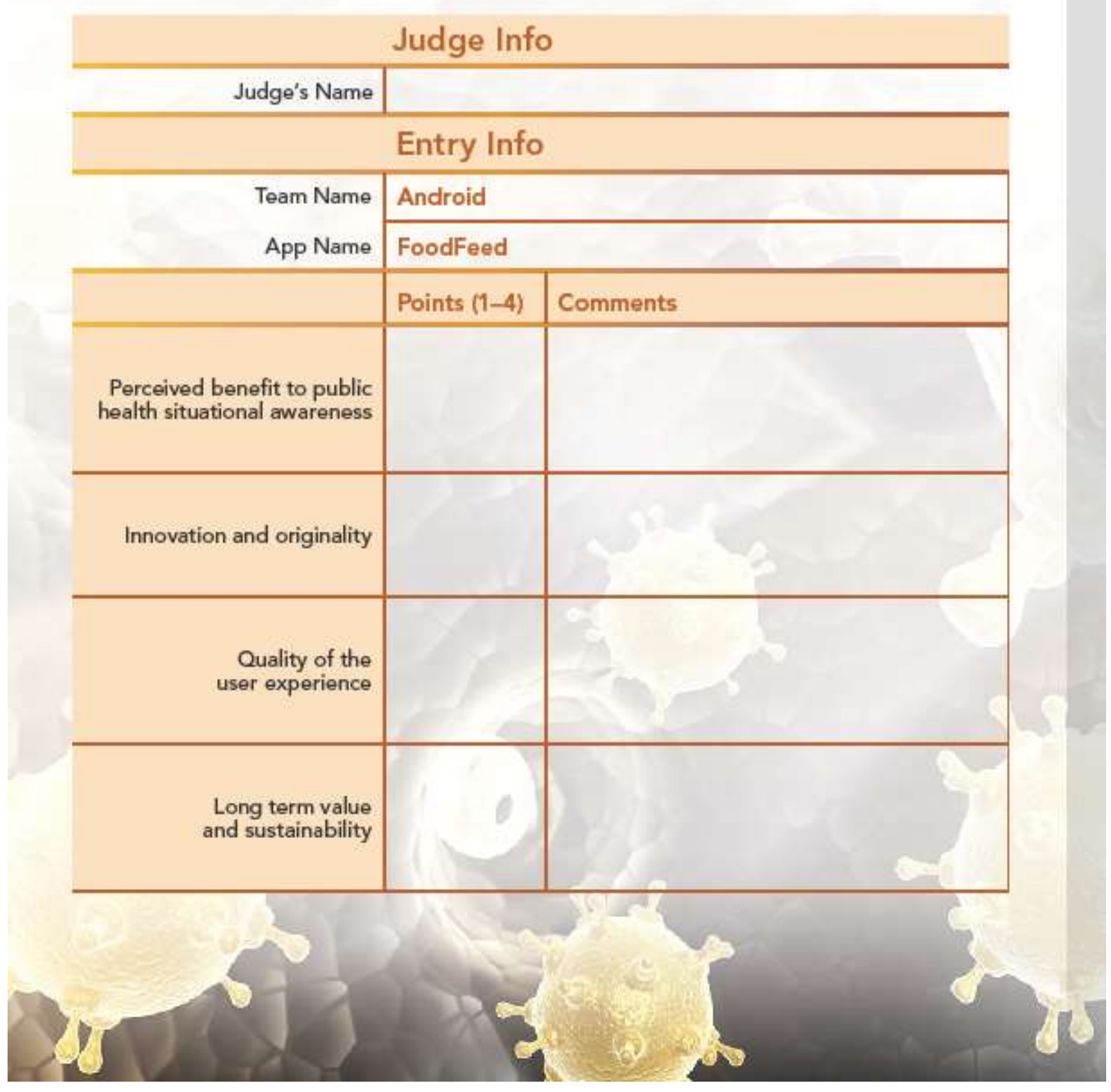





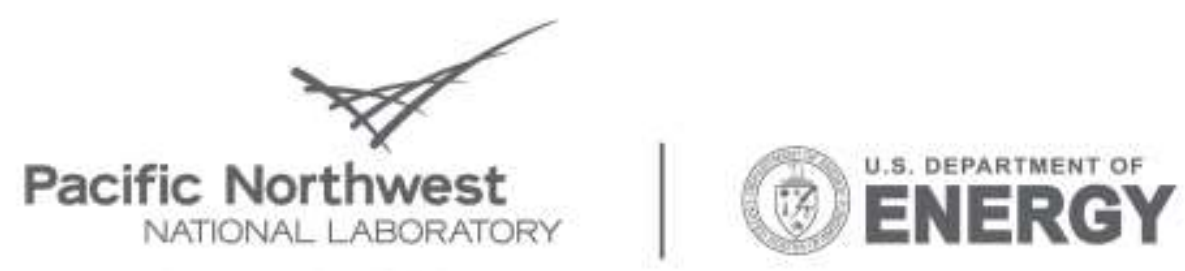

Proudly Operated by Ballelle Since 1965

902 Battelle Boulevard

P.O. Box 999

Richland, WA 99352

1-888-375-PNNL (7665)

www.pnl.gov 